\title{
Economic trade-offs between genetic improvement and longevity in dairy cattle ${ }^{1}$
}

\author{
A. De Vries ${ }^{2}$ \\ Department of Animal Sciences, University of Florida, Gainesville 32611
}

\begin{abstract}
Genetic improvement in sires used for artificial insemination (AI) is increasing faster compared with a decade ago. The genetic merit of replacement heifers is also increasing faster and the genetic lag with older cows in the herd increases. This may trigger greater cow culling to capture this genetic improvement. On the other hand, lower culling rates are often viewed favorably because the costs and environmental effects of maintaining herd size are generally lower. Thus, there is an economic trade-off between genetic improvement and longevity in dairy cattle. The objective of this study was to investigate the principles, literature, and magnitude of these trade-offs. Data from the Council on Dairy Cattle Breeding show that the estimated breeding value of the trait productive life has increased for $50 \mathrm{yr}$ but the actual time cows spend in the herd has not increased. The average annual herd cull rate remains at approximately $36 \%$ and cow longevity is approximately $59 \mathrm{mo}$. The annual increase in average estimated breeding value of the economic index lifetime net merit of Holstein sires is accelerating from $\$ 40 / y \mathrm{r}$ when the sire entered AI around 2002 to $\$ 171 /$ yr for sires that entered AI around 2012. The expectation is therefore that heifers born in 2015 are approximately $\$ 50$ more profitable per lactation than heifers born in 2014. Asset replacement theory shows that assets should be replaced sooner when the challenging asset is technically improved. Few studies have investigated the direct effects of genetic improvement on optimal cull rates. A 35-yr-old study found that the economically optimal cull rates were in the range of 25 to $27 \%$, compared with the lowest possible involuntary cull rate of $20 \%$. Only a small effect was observed of using the best surviving dams to generate the replacement heifer calves. Genetic improvement from sires had little effect
\end{abstract}

\footnotetext{
Received August 8, 2016.

Accepted December 21, 2016.

${ }^{1}$ Presented as part of the ADSA Southern Section Symposium: Strategies for Managing Heifers in the Southeast at the ADSA-ASAS Joint Annual Meeting, Salt Lake City, Utah, July 2016.

${ }^{2}$ Corresponding author: devries@ufl.edu
}

on the optimal cull rate. Another study that optimized culling decisions for individual cows also showed that the effect of changes in genetic improvement of milk revenue minus feed cost on herd longevity was relatively small. Reduced involuntary cull rates improved profitability, but also increased optimal voluntary culling. Finally, an economically optimal culling model with prices from 2015 confirmed that optimal annual cull rates were insensitive to heifer prices and therefore insensitive to genetic improvement in heifers. In conclusion, genetic improvement is important but does not warrant short cow longevity. Economic cow longevity continues to depends more on cow depreciation than on accelerated genetic improvements in heifers. This is confirmed by old and new studies.

Key words: hereditary, profit, culling, survival

\section{INTRODUCTION}

Genetic improvement occurs when animals are mated such that the offspring is superior to the population in terms of the breeding goal. Genetic improvement per unit of time in a trait is the result of selection intensity, accuracy of identification of superior parent(s), the genetic variation in the population for the trait of interest, and the generation interval (Falconer et al., 1996). The marketed AI sires are the result of a very high selection intensity and reasonably high accuracy. Artificial insemination sires are therefore vastly superior to the general population they are selected from. The advent of genomic testing at a young age and improved management suggests that genetic improvement among the available sires is increasing (CDCB, 2016; GarciaRuiz et al., 2016). This trend also results in accelerated genetic improvement in heifers and cows.

Genetic lag is the difference in genetic merit between sires and dams (or more in general, between different populations). If an average cow is successfully mated with a genetically superior sire, it takes approximately 33 mo before the heifer born from this mating to calve for the first time and to start producing milk. This heifer is expected to be genetically between her generically improved sire and her genetically less improved 
dam. The longer the cow stays in the herd, the greater the genetic lag between herself and genetically improved heifers. Culling therefore affects the genetic lag in the herd. If cow cull rates are low, then longevity is high (average longevity $=$ age at first calving +1 / annual cull rate), which means that the average cow is older and has a lower genetic merit than a herd of average age. Thus, increased longevity is associated with greater genetic lag.

A greater genetic lag implies a greater opportunity cost of missed performance because the genetic merit of the average cow in the herd is not as high as that of younger animals. On the other hand, increased longevity also means lower annual cow depreciation cost, given that generally the cost to obtain a heifer is substantially greater than the cow's cull price. An older herd has more mature cows, which affect the herd's performance through milk production, reproduction, health, and so on. Greater longevity could be the result of poor reproduction where open cows continue to be inseminated late in lactation or a low supply of heifers results in less culling, or both. On the other hand, greater longevity may be a result of reductions in culling due to nonpregnancy and health problems, which explain the majority of culling (Dechow and Goodling, 2008; Pinedo et al., 2010). Greater longevity may also increase cow salvage values. Achieving greater longevity through improved cow health will improve cow welfare. Greater longevity may also improve the environmental footprint of milk and dairy beef production because fewer heifers need to be raised (Garnsworthy, 2004; Hristov et al., 2013).

When cow culling is reduced or reproductive efficiency is improved, there is an opportunity to create more heifer calves in the herd than are needed to replace culled cows. Advanced reproductive technologies, such as sexed semen and embryo transfer, are able to produce more heifer calves, or may be used to produce heifer calves from the most desirable dams in the herd, or both (e.g., Hjortø et al., 2015; Kaniyamattam et al., 2016). In addition, genetic selection among the born heifer calves can further increase the average genetic merit of heifers selected to enter the herd (e.g., Weigel et al., 2012). Therefore, the trade-off between increasing longevity and the opportunity cost of genetic improvement foregone in the herd, in combination with reproductive technologies, is complex and the problem of finding the optimum balance has not been solved.

The review and analysis in this study are limited to the direct trade-off between genetically improved heifers and cow longevity. No attempt is made to review all available literature that may shed light on the optimal mix of decisions regarding cow longevity, reproductive technologies, selection of dams, heifers, and sires.
The objectives of this paper are therefore 2-fold. First, I describe genetic trends and genetic lag in dairy cattle in the United States to identify the opportunity cost of genetic improvement foregone. I also present data on longevity. Second, I review literature on the direct trade-off between longevity and genetic improvement, identify shortcomings, present some additional illustrative calculations, and draw conclusions. Parts of this article are based on De Vries (2015).

\section{GENETIC TRENDS, GENETIC LAG, AND LONGEVITY}

\section{Genetic Trend and Lag}

Annual genetic trends for various traits (milk, fat, protein, productive life, SCS, daughter pregnancy rate, heifer conception rate, cow conception rate, calving ease, and stillbirth) and for several dairy breeds in the US are available from the CDCB (2016). The CDCB also presents trends in the economic indexes of lifetime net merit (NM\$), cheese merit, fluid merit, and grazing merit (VanRaden, and Cole, 2014). The NM\$ is the expected lifetime profit compared with an animal with an EBV of NM\$ of 0 . Currently, the EBV of all traits of cows born in 2010 are set to 0 .

The trend in milk yield (Figure 1) shows that the EBV of milk yield for cows continuously lags behind those for the sires of these cows. From 2000 to 2014, this lag was on average $296 \mathrm{~kg} / 305 \mathrm{~d}$. The lag between the EBV for the sires and dams of these cows is estimated to be twice this difference $(593 \mathrm{~kg} / 305 \mathrm{~d})$. These lags have been fairly constant for almost $40 \mathrm{yr}$. In the same time period, the annual increase in milk EBV was $62.2 \mathrm{~kg} / 305 \mathrm{~d}$ for sires, $63.7 \mathrm{~kg} / 305 \mathrm{~d}$ for cows, and 65.2 $\mathrm{kg} / 305 \mathrm{~d}$ for dams.

The genetic trends for many other traits are not as constant over time as those for milk yield, fat, and protein. Most of these traits were later introduced and subsequently were only then included in the selection indices such as $\mathrm{NM} \$$.

Looking at these trends for daughter pregnancy rate (DPR, the percent eligible animals that got pregnant in a 21-d period), we observe sire EBV that were lower than cow EBV for DPR from 1957 (the first year the data are available) to 2011. Only since 2012 is the sire EBV greater than the cow EBV for DPR. This is the result of increased selection for functional traits such as DPR since the 1990s.

From 1960 to approximately 1985, the EBV for productive life (approximately the time from first calving to culling) for the sires of the cows was approximately 1.71 mo longer than for cows (Figure 2). The trend was approximately 0.31 more months per year for cows, 


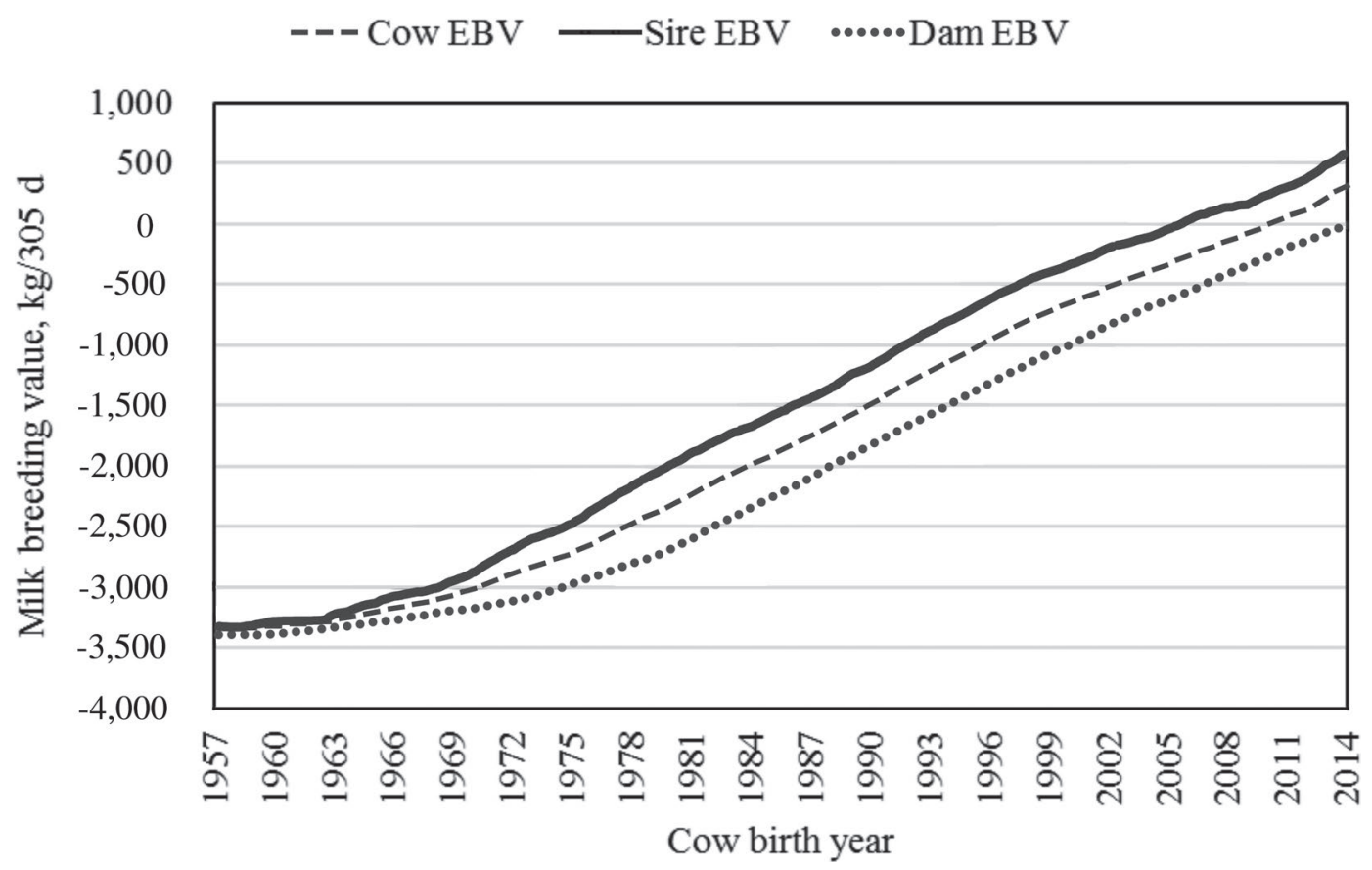

Figure 1. Trend in milk EBV for US Holsteins or Red and White, calculated in April 2016 (in $\mathrm{kg}$ ). The sire EBV is the average EBV of the sires of the cows. The dam EBV is the average EBV of the dams of the cows, calculated as (cow EBV - sire EBV $/ 2$ ) $\times 2$. The cow milk EBV lags behind the sire milk EBV by on average $296 \mathrm{~kg} / 305 \mathrm{~d}$ (2000 to 2014). The lag between the dam and sire EBV is twice this difference. Source: CDCB (2016).

sires, and dams. From 1985 to approximately 2000, the trend for sires was about 0 whereas the cow EBV increased. The sire EBV lagged 0.25 mo behind the cow EBV in 2000, but in 2013 the sire EBV led again by $1.57 \mathrm{mo}$, a result of an increased emphasis on selection for productive life. Although the EBV for productive life showed increases over time, the phenotypic productive life decreased until 2008. The actual time cows stayed in the herd therefore decreased.

Trends in EBV of NM\$, calculated with the 2014 formula (VanRaden and Cole, 2014), are shown in Figure 3. From 1980 to 2009 , the trends were fairly linear and increased approximately $\$ 44$ per year for cows and their sires and dams. With the standard deviation of true breeding value of $\$ 388$ (VanRaden and Cole, 2014), this is an increase of 0.11 standard deviation per year. The average difference between the sire EBV and the cow EBV for NM $\$$ was $\$ 322$, and between the sire and dam EBV therefore $\$ 622$.

Figure 3 shows an increase in annual genetic trend for $\mathrm{NM} \$$ in the most recent years. For cows born in 2010 to 2014, the annual trends in the EBV of NM\$ were $\$ 94$ for cows and $\$ 117$ for their sires. This equates to increases of 0.30 and 0.24 standard deviation of $\mathrm{NM} \$$ per year. For 2014, the sire EBV was $\$ 580$ greater than the cow EBV.
The average annual gain in $\mathrm{EBV}$ of $\mathrm{NM} \$$ for marketed Holstein sires was $\$ 40$ (sire entered AI in 2000 to 2004 ), $\$ 104$ (2005 to 2009 ) and $\$ 171$ (2010 to 2014; G. Wiggans, USDA-ARS, Beltsville, MD, personal communication). These are increases of $0.10,0.26$, and 0.43 standard deviation of $\mathrm{NM} \$$ per year. The latest acceleration is due to rapid adoption of genomic testing since 2009, which has reduced generation interval of sires dramatically and improved the rate of genetic gain (Hutchison et al., 2014; Garcia-Ruiz et al., 2016). Mean sire age for Holstein male offspring born in 2012 was 2.7 yr younger than males born in 2006, and 1.43 yr younger for females.

Using data from progeny-tested Holstein bulls born from 2002 to 2006, USDA-ARS expects genetic improvement in EBV for NM $\$$ to be 0.45 standard deviation (VanRaden and Cole, 2014). Multiplying the expected EBV change by their economic values results in a gain of $\$ 149 /$ yr. It also means that each year heifers will on average get better by up to $\$ 149 \mathrm{NM} \$$ if the genetic trend in their dams is similar, although their genetic level will be lower (the genetic lag). Because $\mathrm{NM} \$$ is a lifetime value (2.8 lactations or approximately $3 \mathrm{yr}$ ), we can expect that heifers born in 2015 are about $\$ 50$ more profitable per year than heifers born in 2014 ( $\$ 149 / 3$ yr). The increase in profitability calculated from the 


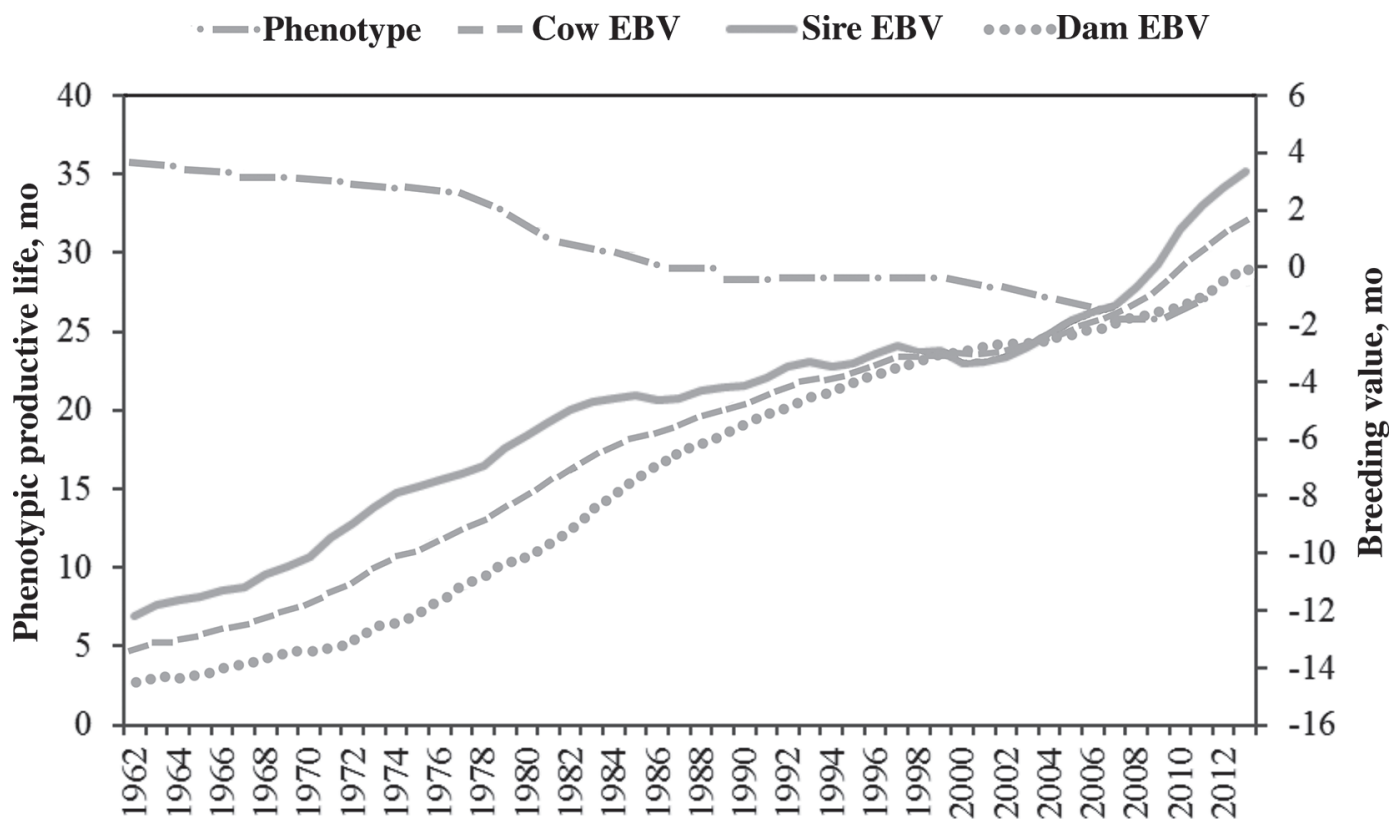

Figure 2. Trend in EBV and phenotype of productive life for US Holsteins or Red and White, calculated in April 2016. The sire EBV is the average EBV of the sires of the cows. The dam EBV is the average EBV of the dams of the cows, calculated as (cow EBV - sire EBV/2) $\times 2$. The EBV for productive life increased, but phenotypic productive life decreased until 2008. Source: CDCB (2016).

other selection indices is similar. Quantification of the rate of genetic improvement in $\mathrm{NM} \$$ is useful when estimating the economic trade-off between accelerated genetic gain and phenotypic longevity.

\section{Phenotypic Longevity}

The phenotypic trend in productive life suggests that the actual time cows stayed in the herd has remained

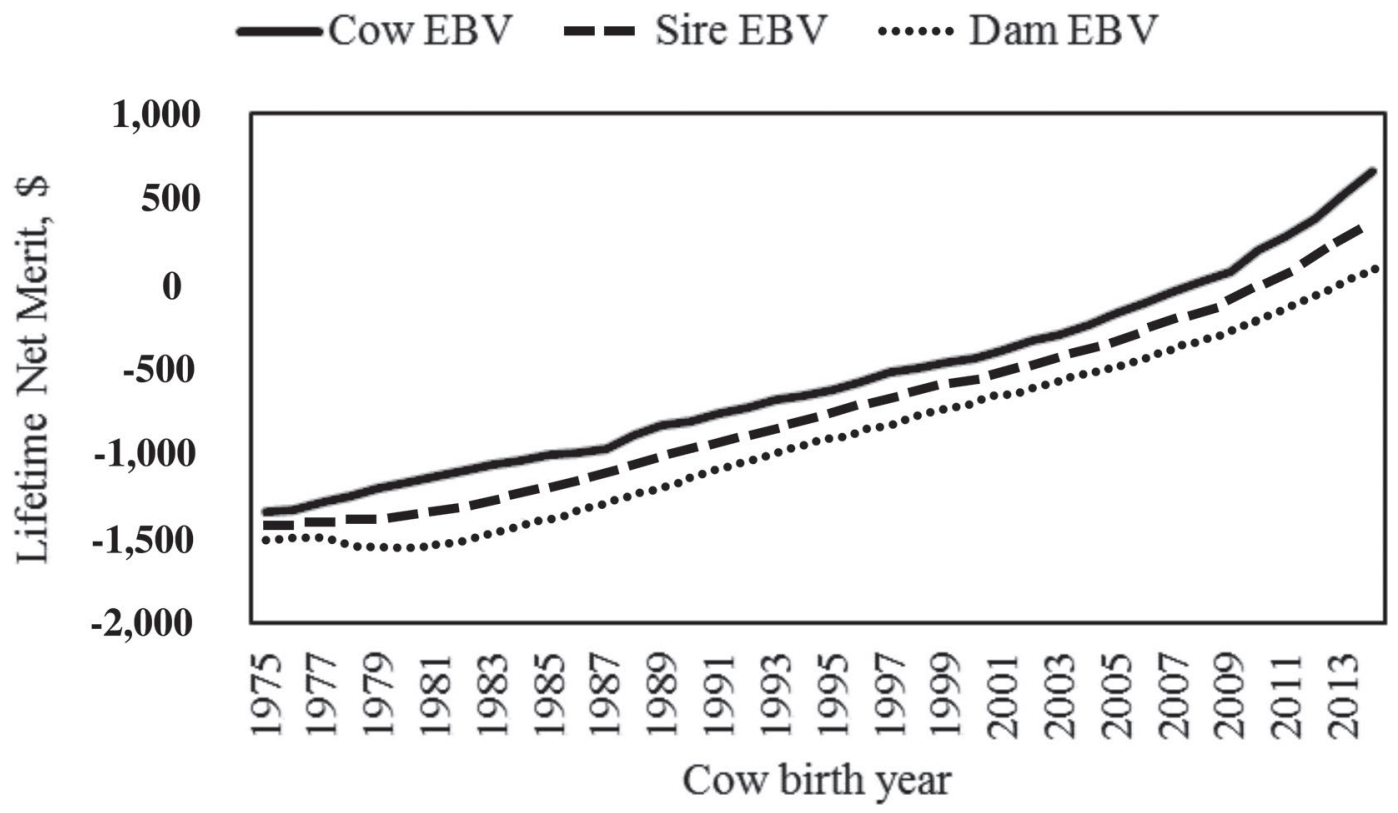

Figure 3. Trend in EBV of lifetime net merit (NM\$) for US Holsteins or Red and White, calculated in April 2016. The sire EBV is the average EBV of the sires of the cows. The dam EBV is the average EBV of the dams of the cows, calculated as $($ cow EBV - sire EBV/2) $\times 2$. The annual trends in EBV for NM\$ increased in the most recent years. Source: CDCB (2016). 
Table 1. Association between annual cow cull rates and herd statistics for 9,755 US Holstein dairy herds participating in the DHI program ${ }^{1}$

\begin{tabular}{lccrrrrr}
\hline & \multicolumn{7}{c}{ Annual cow cull rate, \% } \\
\cline { 2 - 7 } Herd statistic & \multicolumn{1}{c}{$14-20$} & $21-27$ & $28-34$ & $35-41$ & $42-48$ & $49-55$ & $56-62$ \\
\hline Herds, no. & 395 & 1,304 & 2,511 & 2,580 & 1,540 & 561 & 250 \\
Cows left per year, \% & 17.8 & 24.6 & 31.2 & 37.9 & 44.6 & 51.5 & 58.4 \\
Cows, no. & 87.8 & 131.6 & 183.5 & 236.6 & 212.0 & 181.4 & 151.5 \\
Change in herd size, \% & 11.2 & 7.8 & 3.9 & 2.0 & -0.7 & -2.0 & -4.9 \\
Rolling milk yield, kg/yr & 8,866 & 9,715 & 10,246 & 10,533 & 10,625 & 10,440 & 10,274 \\
Calvings per cow per year, \% & 89.9 & 97.7 & 102.2 & 106.7 & 110.8 & 115.2 & 119.9 \\
Heifers present per cow, \% & 71.8 & 79.5 & 85.1 & 92.3 & 97.8 & 102.5 & 101.1 \\
Pregnancy rate, \% & 17.2 & 17.9 & 18.6 & 19.3 & 18.9 & 18.4 & 18.8 \\
NM\$ for cows & -19.5 & 2.6 & 25.2 & 38.8 & 49.3 & 34.9 & 36.2 \\
NM\$ for heifers & 115.7 & 138.9 & 157.1 & 165.2 & 170.9 & 153.5 & 148.7 \\
Age of first calving, mo & 27.4 & 26.5 & 25.8 & 25.5 & 25.4 & 25.6 & 25.6 \\
Longevity, mo & 94.8 & 75.3 & 64.3 & 57.2 & 52.3 & 48.9 & 46.1 \\
\hline
\end{tabular}

${ }^{1}$ Source: DRMS (2016).

${ }^{2} \mathrm{NM} \$=$ lifetime net merit.

fairly constant in the last $50 \mathrm{yr}$, although the EBV for productive life increased. The average annual cull rate in 9,755 US Holstein herds participating in the DHI program processed by DRMS was 36\% (DRMS, 2016). With the average age of first calving at 25.8 mo, the average longevity was $58.9 \mathrm{mo}(4.9 \mathrm{yr})$. Table 1 shows associations between the annual cow cull rate and various herd statistics from these cows on DHI test. The highest cull rates are associated with more calvings per cow per year, and more heifers present per cow. Associations with herd size, reproduction, milk production, and genetics are less clear, with the more desirable statistics found for medium cull rates and therefore medium longevity.

Cow culling is the result of many factors other than the EBV of productive life, such as milk production, reproduction, prices, and the availability of heifers. Nationally, the average cull rate equals the number of dairy heifers that are raised annually (approximately 3.2 million) divided by the average national dairy herd size (approximately 9.1 million cows), given little export of heifers. Therefore, the national average cow longevity will remain primarily a function of the number of heifers that are raised per dairy cow present. Individual farms have some flexibility to adjust their cow culling, especially to increase it.

Annual cow depreciation, calculated as the difference in the cost to obtain the calving heifer and the salvage value of the culled cow, can be several hundreds of dollars per cow year. Both the cost to obtain heifers and salvage values can vary greatly within a few years. From 2000 to 2015, USDA-NASS (2016) reported average cull prices of $\$ 1.27 / \mathrm{kg}$ of $\mathrm{BW}$, which is $\$ 764$ for a $600-\mathrm{kg}$ cow. This is generally approximately half of the cost of purchasing a heifer (Frazer LLP, 2016), although the cost of raising a heifer can be substantially greater.

\section{TRADE-OFF BETWEEN GENETIC IMPROVEMENT AND LONGEVITY}

\section{Illustrative Example}

A simple calculation may illustrate the trade-off between genetic lag opportunity cost and depreciation. Assumptions are that age at first calving is $2 \mathrm{yr}$, profit per cow per year excluding depreciation is the same for every parity, the cost to obtain a heifer is $\$ 2,000$, and the salvage value is $\$ 1,500$ regardless of age. Further assume an annual genetic improvement of $\$ 150$ profit per lifetime (assumed to be 3 yr for simplicity), which is $\$ 50$ profit per year. When the annual cull rate is $35 \%$, then longevity is $4.86 \mathrm{yr}$, which includes $2 \mathrm{yr}$ as a heifer and $2.86 \mathrm{yr}$ as a cow. The average age of a cow in the herd is then $3.43 \mathrm{yr}$. Therefore, the opportunity cost of the genetic lag is $3.43 \times \$ 50=\$ 171 / \mathrm{yr}$. The depreciation cost is $(\$ 2,000-\$ 1,500) / 2.83=\$ 175 /$ yr. Collectively, these costs are $\$ 346 /$ yr. When annual cull rates are $15,25,45$, or $55 \%$, then the annual genetic opportunity costs are $\$ 267, \$ 200, \$ 156$, and $\$ 145$, whereas annual depreciation costs are $\$ 75, \$ 125, \$ 225$, and $\$ 275$. Total costs are therefore $\$ 342, \$ 325, \$ 381$, and $\$ 420$. In this case, the $25 \%$ cull rate results in the minimum total cost, whereas lower and higher cull rates result in greater costs. Reducing salvage value to $\$ 1,000$ results in the lowest total cost for the lowest cull rate, and hence favors the greatest longevity. Similarly, reducing annual genetic improvement favors greater longevity. Variations in annual genetic improvement $(\$ 75$ to $\$ 225)$ and depreciation costs $(\$ 500$ to $\$ 1,500)$ typically favor the lower annual cull rates and hence favor greater longevity. The pull of genetic improvement is not strong enough to trigger increased culling greatly. The optimal cull rate is as high as possible when the 
depreciation cost is zero ( $\$ 2,000$ salvage value). When genetic improvement doubles from $\$ 150$ to $\$ 300$, total cost increases for all annual cull rates and all salvage values considered, and the optimal cull rate increases.

These simple calculations ignore many important factors, such as inherent differences in profitability between parities, and how cull rates might be changed, including their effects on the cows that remain in the herd. For example, the optimum cull rate would be lower when considering that more mature cows are more profitability. Also not included is the availability of raised heifers to replace culled cows. When longevity is shorter, more dairy calves need to be produced or the herd will need to purchase heifers not born in the herd. When longevity is greater, surplus dairy calves are present that could be sold, or fewer dairy calves could be created, for example by using beef semen in the herd. Differences in reproductive efficiency may affect cow cull rates and the availability of dairy calves.

\section{Asset Replacement Theory}

With evidence that genetic improvement is accelerating, the question is how genetic improvement in replacement heifers should affect cow culling and therefore longevity. The review here is limited to cases where the supply of heifers does not determine the number of cows that are culled, but rather the optimal cull rate, and hence longevity, is optimized independently. Replacing cows with genetically superior heifers is an application of the general problem of asset replacement with technologically improved assets. Optimal asset replacement theory has been studied for almost $100 \mathrm{yr}$, and the pertinent engineering literature was recently reviewed by Hartman and Tan (2014). Perrin (1972) described the basic marginal principle of asset replacement which is "to compare gains from keeping the current asset for another time interval with the opportunity gains which could be realized from a replacement asset during the same period."

Groenendaal et al. (2004) summarized this standard economic theory in terms of cow replacement, showing also that in theory cows should be replaced sooner when the incoming heifers are genetically improved. The theory indicates that "the optimum time for replacement of a dairy cow is determined by comparison of the marginal net revenue anticipated from the present cow with the economic opportunity of a replacement. The latter value equals the maximal average discounted net revenue anticipated from replacement cows, also reported as annuities. For a situation with identical replacement or genetically improved replacement, the optimum time of replacement is defined as the first time period in which the annuity value of the cow drops below the maximal annuity value of the replacement animal" (Groenendaal et al., 2004).

The criterion here is the maximization of total discounted expected net revenue per present cow. Most studies that calculated optimal herd cull rates by optimizing individual cow culling decisions have assumed this criterion (e.g., DeLorenzo et al., 1992; Groenendaal et al., 2004; De Vries, 2006). These studies used expectations based on weighted averages of the various anticipated biological risks. Kristensen (1989) pointed out that in a situation with herd milk quotas as the most limiting factor, the theoretically correct criterion is the maximization of net revenue per kilogram of milk produced. In the case of milk quota, optimal cull rates are lower than when the number of present cows is the most limiting factor. De Vries (2004) optimized cull rates when the number of cow slots is most limiting, allowing for not immediate replacement in very seasonal herds. Therefore, optimal cow longevity depends on the most limiting farm factor. These studies did not consider the effect of genetic improvement on cow culling decisions.

\section{Review of Literature}

Few studies have tried to address the trade-off question of culling versus genetic improvement. A complete analysis considering all effects is complicated because there are interacting effects of (at least): (1) involuntary cow culling, (2) voluntary cow culling, (3) choice of dams to supply the next generation of replacement heifers, (4) number of heifers required to replace culled cows, (5) genetic improvement from sires, and (6) from selection among heifers. In these model studies, involuntary culling is a user-defined hazard of culling, whereas voluntary culling is determined by the model to improve the value of the objective function. Although the distinction between involuntary and voluntary culling is clear in modeling studies, Fetrow et al. (2006) recommended against this distinction in practice.

A rather complete but now old study is from Allaire (1981). He included all 5 factors to determine optimal cull rates, as well as the increase in milk sold per cow and increase in profitability after $20 \mathrm{yr}$ of culling and selection. The model included culling and selection based on milk yield only. In the model, he assumed that young stock culling was proportional to cow culling, so when cow culling was increased, so was young stock culling. He found that optimal cull rates were 30 to $35 \%$ when the objective was maximum milk sold per cow. The gain from keeping heifers from random survivor dams after voluntary culling was slightly smaller than the effect of voluntary culling only for low milk yield around the $35 \%$ cull rate. This effect of culling 
was equivalent to at least $25 \mathrm{yr}$ of genetic gain from dam selection. When the calves from the best dams among the survivor dams were used to generate the next generation of heifers, the additional gain was quite small because at a $35 \%$ cull rate, few surplus dams were available. Thus selection intensity in dams was low at higher cull rates. No genetic improvement from sires was considered in these cases. Considering a $0.5 \%$ annual increase in milk yield from sires, the improvement was equivalent to the gain from breeding the best surviving dams and voluntary culling. These optimums around $35 \%$ cull rates to maximize milk yield do not include the depreciation cost of cows. These depreciation costs are greater at $35 \%$ cull rates than at lower cull rates.

When Allaire (1981) included depreciation costs that were relevant in Ohio in 1979, he found that the economically optimal female cull rates were in the range of 20 to $23 \%$, only 0 to 3 percentage points above the minimum $20 \%$ involuntary cull rate he assumed. Expressed per cow, the economic optimal cull rates were in the range of 25 to $27 \%$, compared with an involuntary cull rate of $20 \%$. Only a small effect was observed of using the best surviving dams compared with random surviving dams to generate the replacement heifer calves. Allaire's (1981) findings that a much reduced cull rate would maximize profitability, at the cost of genetic improvement, were suggested earlier by Hill (1980). Therefore, significant cow depreciation reduced optimal cull rates. Genetic improvement from both selection and culling among dams, and from genetic improvement among sires, was reduced. Although the method Allaire used is elegant, the results are somewhat outdated because of assumptions in prices, milk yield, and lower annual genetic improvement in sires.

Van Arendonk (1985) studied optimal replacement policies in dairy cattle, including the effects of genetic increases in milk yield. These optimal culling policies were much more detailed than those assumed by Allaire (1981) and were economically optimal, but genetic improvement from the dam side, either through voluntary culling or generating offspring from the genetically better dams, was not implicitly modeled. Annual genetic improvement in heifers was set at $\$ 5.45, \$ 10.91$, or $\$ 21.82$ (1985 values, or $\$ 12, \$ 24$, or $\$ 48$ in 2016 dollars). Optimal annual cull rates changed only from 27 to $30 \%$ with the greater genetic improvement and also increased profitability. The proportion of culled cows for which replacement was voluntary, instead of involuntary, increased from 23 to $32 \%$. Reduced involuntary cull rates improved profitability, but also simultaneously increased optimal voluntary culling. Van Arendonk (1985) concluded that the effect of changes in genetic increases in milk revenue minus feed cost on the average herd longevity was small. Therefore, he further concluded that from an economic point of view management and breeding policies should be directed toward reduction of involuntary disposal rather than maximization of the average longevity of cows through less voluntary culling.

\section{Reduced Herd Entry Cost Illustration}

The final analysis is again illustrative. A genetically improved heifer with an EBV of $\$ 100 \mathrm{NM} \$$ is expected to be approximately $\$ 33$ more profitable per year than an average heifer with an EBV of $\$ 0$. Considering discounting for future income into today's heifer value, and considering that the genetically improved heifer's offspring are also expected to be somewhat more improved than average, I calculated this combined factor to be 1.4 to put the EBV of $\$ 100 \mathrm{NM} \$$ into today's net present value of $+\$ 140$. When the cost to obtain a heifer does not include her genetic merit, then a corollary is that the herd entry cost of the $\$ 100 \mathrm{NM} \$$ heifer is $\$ 140$ lower than the herd entry cost of the average heifer. If the average heifer costs $\$ 2,000$, then the herd entry cost of this genetically improved heifer can be assessed to be only $\$ 1,860$. The analysis then is to investigate the effect of a lower herd entry cost on the optimal cull rate. This approach is similar to the approach used by Van Arendonk (1985). Note that the EBV of NM\$ of the sires tracked by CDCB (2016) increased annually from $\$ 43$ (1980 to 2009 ) to $\$ 117$ (2010 to 2014 ) and may be expected to increase to $\$ 150 / \mathrm{yr}$.

Using updated inputs for a typical US dairy herd in 2014 and a model (De Vries, 2004, 2006) similar to the one used by Van Arendonk (1985) that optimized individual cow culling decisions, I varied herd entry prices and observed optimal cull rates as well as the surplus of dairy heifer calves generated. Surplus dairy heifer calves occur if the number of calves available for replacement is greater than the number needed to replace culled cows. Some key results are in Table 2 for 2 levels of estrus detection rate leading to pregnancy rates of approximately 25 and $20 \%$.

Table 2 shows again that annual optimal cull rates are somewhat insensitive to heifer prices (herd entry cost) and therefore insensitive to accelerated genetic improvements in heifers. With lower heifer prices, profitability increased, the optimal annual cull rate increased, and the number of surplus heifer calves decreased. A negative surplus implies that the herd has a shortage of heifer calves and additional heifers need to be purchased.

In the case of the lower pregnancy rate $(20 \%)$, surplus was zero when the heifer price was $\$ 1,590$. Using the culling policy associated with the $\$ 1,590$ heifer price, 
Table 2. Optimal annual cull rate and surplus of dairy heifer calves as a function of herd entry cost (heifer price) calculated with a model (De Vries 2004, 2006) with economically optimal culling decisions and 2 levels of reproductive performance ${ }^{1}$

\begin{tabular}{lcccr}
\hline Herd entry cost, $\$$ & Profit, $\$$ /cow per yr & Pregnancy rate, $\%$ & Annual cull rate, $\%$ & Surplus heifer calves, $\%$ \\
\hline 1,400 & 818 & 25 & 59 & -22 \\
1,600 & 720 & 25 & 41 & 34 \\
1,800 & 647 & 25 & 30 & 21 \\
2,000 & 584 & 24 & 28 & 32 \\
2,200 & 526 & 24 & 64 & -30 \\
1,400 & 801 & 21 & 36 & 2 \\
1,600 & 696 & 20 & 32 & 22 \\
1,800 & 617 & 20 & 30 & 26 \\
2,2000 & 550 & 20 & & \\
\hline
\end{tabular}

${ }^{1}$ A lower herd entry cost is a proxy for a heifer with a fixed raising cost but with greater genetic merit.

the profits per cow per year were $\$ 16, \$ 10$, and $\$ 60$ lower when heifer prices were $\$ 1,400, \$ 1,800$, and $\$ 2,200$, respectively, compared with profits associated with the optimal culling policy. Similarly, a $\$ 1,530$ heifer price let to approximately $0 \%$ surplus calves when pregnancy rate was approximately 25\%. Again using the policy associated with the $\$ 1,530$ heifer price, profits per cow per year were $\$ 8, \$ 21$, and $\$ 84$ lower when heifer prices were $\$ 1,400, \$ 1,800$, or $\$ 2,200$ compared with profits from the optimal policy.

The results show, in agreement with the older results of Allaire (1981) and Van Arendonk (1985), that the expected accelerated genetic improvement in sires is not fast enough to warrant a high cull rate (resulting in a short longevity) and bring all heifer calves into the herd.

\section{DISCUSSION}

Genetic improvement in AI sires is increasing compared with just a decade ago as a result of genetic testing and a shorter generation interval. This means that faster genetic improvement through AI sires also results in faster genetic improvement in heifers. Following asset replacement theory, this means that cows should be replaced a little faster, thereby decreasing the time cows spend in the herd. The expected accelerated genetic improvement reduces the economically optimal longevity somewhat. Optimal voluntary culling, and therefore cow longevity, continues to be more dependent on the difference between heifer raising cost and cow cull prices than on genetic improvement.

As mentioned, a longer lifespan in cows may also reduce the environmental effect of dairy production because fewer replacement heifers need to be raised. A low cull rate, leading to more older cows, may also be associated with greater cow welfare (Oltenacu and Algers, 2005). When a surplus of heifer calves can be created, some options are to sell some heifer calves, perhaps after genomic testing (see for example Kani- yamattam et al., 2016), use of beef semen, or both. A delay in voluntary waiting period for first insemination for some cows might also reduce the number of heifer calves born per year. The ideal combination of culling and reproductive technologies has not yet been determined, however.

\section{CONCLUSIONS}

The evidence collected in this article suggests that the major way to capture the recently accelerating genetic improvement in sires is not by greatly increasing cow culling and hence reducing longevity. This is confirmed by old and new studies.

\section{ACKNOWLEDGMENTS}

This study was financially supported by USDANational Institute of Food and Agriculture (NIFA) Agriculture and Food Research Initiative (AFRI) grant award 2013-68004-20365 titled "Improving Fertility of Dairy Cattle Using Translational Genomics."

\section{REFERENCES}

Allaire, F. R. 1981. Economic consequences of replacing cows with genetically improved heifers. J. Dairy Sci. 64:1985-1995.

CDCB (Council on Dairy Cattle Breeding). 2016. Bovine Genetic Trends. Accessed Aug. 8, 2016. https://www.uscdcb.com/eval/ summary/trend.cfm.

Dechow, C. D., and R. C. Goodling. 2008. Mortality, culling by sixty days in milk, and production profiles in high- and low-survival Pennsylvania herds. J. Dairy Sci. 91:4630-4639.

DeLorenzo, M. A., T. H. Spreen, G. R. Bryan, D. K. Beede, and J. A. M. Van Arendonk. 1992. Optimizing model: Insemination, replacement, seasonal production, and cash flow. J. Dairy Sci. 75:885-896.

De Vries, A. 2004. Economic value of delayed replacement when cow performance is seasonal. J. Dairy Sci. 87:2947-2958.

De Vries, A. 2006. Economic value of pregnancy in dairy cattle. J. Dairy Sci. 89:3876-3885

De Vries, A. 2015. Culling/longevity versus genetic progress from heifers. Advances in Dairy Technology 27:345-355.

DRMS (Dairy Records Management Systems). 2016. Dairy Metrics. Accessed Aug. 5, 2016. http://www.drms.org. 
Falconer, D. S., T. F. Mackay, and R. Frankham. 1996. Selection: The response and its prediction. Pages 184-207 in Introduction to Quantitative Genetics. 4th ed. Longmans GreenHarlow, Essex, UK.

Fetrow, J., K. V. Nordlund, and H. D. Norman. 2006. Invited review: Culling: Nomenclature, definitions, and recommendations. J. Dairy Sci. 89:1896-1905.

Frazer LLP. 2016. Dairy Farm Operating Trends. Accessed Aug. 8, 2016. http://frazerllp.com/resources/dairy-farm-operatingtrends/.

Garcia-Ruiz, A., J. B. Cole, P. M. VanRaden, G. R. Wiggans, J. F. Ruiz-Lopez, and C. P. Van Tassell. 2016. Changes in genetic selection differentials and generation intervals in US Holstein dairy cattle as a result of genomic selection. Proc. Natl. Acad. Sci. USA 113:E3995-E4004.

Garnsworthy, P. C. 2004. The environmental impact of fertility in dairy cows: A modeling approach to predict methane and ammonia emissions. Anim. Feed Sci. Technol. 112:221-223.

Groenendaal, H., D. T. Galligan, and H. A. Mulder. 2004. An economic spreadsheet model to determine optimal breeding and replacement decisions for dairy cattle. J. Dairy Sci. 87:2146-2157.

Hartman, J. C., and C. H. Tan. 2014. Equipment replacement analysis: A literature review and directions for future research. Eng. Econ. 59:136-153.

Hill, W. G. 1980. Theoretical aspects of culling and selection in dairy cattle. Livest. Prod. Sci. 7:213-224.

Hjortø, L., J. Ettema, M. Kargo, and A. Sørensen. 2015. Genomic testing interacts with reproductive surplus in reducing genetic lag and increasing economic net return. J. Dairy Sci. 98:646-658.

Hristov, A. N., T. Ott, J. Tricarico, A. Rotz, G. Waghorn, A. Adesogan, J. Dijkstra, F. Montes, J. Oh, E. Kebreab, S. J. Oosting, P. J. Gerber, B. Henderson, H. P. S. Makkar, and J. L. Firkins. 2013 Special topics-Mitigation of methane and nitrous oxide emissions from animal operations: III. A review of animal management mitigation options. J. Anim. Sci. 91:5095-5113.
Hutchison, J. L., J. B. Cole, and D. M. Bickhart. 2014. Short communication: Use of young bulls in the United States. J. Dairy Sci 97:3213-3220.

Kaniyamattam, K., M. A. Elzo, J. B. Cole, and A. De Vries. 2016. Stochastic dynamic simulation modelling including multitrait genetics to estimate genetic, technical and financial consequences of dairy farm reproduction and selection strategies. J. Dairy Sci. 99:8187-8202.

Kristensen, A. R. 1989. Optimal replacement and ranking of dairy cows under milk quotas. Acta Agric. Scand. 39:311-318.

Oltenacu, P. A., and B. Algers. 2005. Selection for increased production and the welfare of dairy cows: Are new breeding goals needed? Ambio 34:311-315.

Perrin, R. K. 1972. Asset replacement principles. Am. J. Agric. Econ. 54:60-67.

Pinedo, P. J., A. De Vries, and D. W. Webb. 2010. Dynamics of culling risk with disposal codes reported by Dairy Herd Improvement dairy herds. J. Dairy Sci. 93:2250-2261.

USDA-NASS. 2016. US Monthly Dairy Cow Slaughter. Accessed Aug. 8, 2016. http://future.aae.wisc.edu/data/monthly_values/by_area $/ 2100$ ?area $=$ US\&grid $=$ true\&tab $=$ feed.

Van Arendonk, J. A. M. 1985. Studies on the replacement policies in dairy cattle. II. Optimum policy and influence of changes in production and prices. Livest. Prod. Sci. 13:101-121.

VanRaden, P. M., and J. B. Cole. 2014. Net merit as a measure of lifetime profit: 2014 revision. AIP Research Report NM\$5 (1014). Accessed Aug. 5, 2016. https://aipl.arsusda.gov/reference/ nmcalc-2014.htm

Weigel, K. A., P. C. Hoffman, W. Herring, and T. J. Lawlor Jr. 2012. Potential gains in lifetime net merit from genomic testing of cows, heifers, and calves on commercial dairy farms. J. Dairy Sci 95:2215-2225. 